\title{
A origem do Estado em Hobbes e Nietzsche: convergências e divergências ${ }^{1}$
}

\section{The origin of the State in Hobbes and Nietzsche: convergences and divergences}

\author{
Isabela Gonçalves Dourado \\ Graduação em andamento em Filosofia. Universidade Católica de Pernambuco - UNICAP. Recife, PE - \\ Brasil.
}

Resumo: Em Leviatã, Hobbes levanta a hipótese de que o homem teria fundado o Estado para livrar-se da insegurança em que se encontrava no estágio pré-político, o qual se caracterizava por uma constate guerra de todos contra todos. Nietzsche, por sua vez, na segunda dissertação de Genealogia da moral, defende tese semelhante, a saber: o homem é naturalmente violento e o Estado teria promovido uma espécie de barreira coercitiva capaz de inibir a livre expressão de seus impulsos violentos. Assim teria sido originada a sociedade de paz. Ora, devido à visível congruência entre ambas as perspectivas, colocamos a seguinte problemática: estaria a filosofia de Nietzsche vinculada à corrente contratualista à maneira de Hobbes? Levando em conta essa questão, o objetivo deste artigo é examinar as relações entre a teoria contratualista de Hobbes e a hipótese nietzschiana acerca do surgimento do Estado. Para cumprirmos nossa tarefa, dividiremos o trabalho em três momentos. Primeiramente, realizaremos a exposição da tese hobbesiana acerca da passagem do estado de natureza à sociedade civil. Logo após, debruçar-nos-emos sobre a referida obra nietzschiana, passando ainda pelo tema da má-consciência. Por fim, promoveremos a confrontação teórica entre os dois pontos de vista para tentarmos responder ao problema proposto.

Palavras-chave: Hobbes; Nietzsche; Estado; contratualismo; má-consciência.

Abstract: In the Leviathan, Hobbes raises the hypothesis that man would have founded the State to rid himself of the insecurity in which he was in the pre-political stage, characterized by a constant war of all against all. Nietzsche, in the second dissertation on The Genealogy of Morals, defends a similar thesis, namely that man is naturally violent and the State would have promoted a sort of coercive barrier capable of inhibiting the free expression of his violent impulses. Thereby, the society of peace would have been established. Thus, due to the conspicuous congruences between both perspectives, therefore, we propose this work's question: was nietzsche's philosophy linked to the contractualist current in the Hobbes way? Taking this issue into account, we propose to examine the relationship between Hobbes' contractualist theory and the nietzschean hypothesis about the establishment of the State. To accomplish our task, this work was divided into three moments. First, we will present the hobbesian

\footnotetext{
${ }^{1}$ Este texto é resultado da reformulação de uma comunicação que apresentamos no V Colóquio de Ética e Filosofia Política, em abril de 2018, na Universidade Católica de Pernambuco, Recife.
} 
thesis about the transition from the stage of nature to civil society. Then, we will focus on the aforementioned Nietzschean work, going through the theme of bad conscience. Finally, we will promote a theoretical confrontation between both points of view to try to answer the proposed problem.

Keywords: Hobbes; Nietzsche; State; Contractualism; bad conscience.

\section{A tese contratualista de Hobbes}

As reflexões de Thomas Hobbes acerca da política giram em torno da distinção de dois momentos concernentes a uma hipotética história da humanidade, a saber: o estado de natureza e a sociedade civil' ${ }^{2}$. No estado de natureza, os homens possuiriam o direito natural de usar livremente de toda sua força e poder para se proteger e adquirir tudo que pudessem para garantir sua própria conservação. Contudo, esse estágio mais "primitivo", por assim dizer, caracterizar-se-ia por uma constante ameaça às vidas dos indivíduos, o que levaria ao surgimento do segundo estágio. Neste, entretanto, haveria a intervenção do uso de leis e força coercitiva as quais imporiam aos homens um comportamento limitado pelas regras da vida coletiva. Isto significaria, grosso modo, a perda da liberdade irrestrita - própria do estado de natureza - em troca da proteção. Em outras palavras, a vida é garantida por meio da promoção dos impedimentos legais que proíbem os homens de agir segundo sua condição natural.

\subsection{A condição natural do homem e a relação entre direito natural e leis da natureza}

Para melhor compreender o pensamento do filósofo inglês devemos, antes de tudo, tentar entender como se caracterizaria o homem em seu estado pré-político. Como foi dito, no período anterior à instauração de leis civis, não haveria qualquer tipo de barreira que limitasse as ações dos homens e, por isso, eles gozariam de direitos ilimitados. Isso significa dizer que, em seu estado de natureza, eles se encontram numa condição de igualdade na qual estão completamente livres para usarem de esforços imensuráveis a favor de sua própria vida e do gozo de suas vontades: "porque não há nada a que um homem não tenha direito por natureza" (HOBBES, 1999, p. 114). Ou seja, cada indivíduo possui o direito natural sobre todas as coisas e, no exercício de sua liberdade, ele não identifica a presença de impedimentos que possam inibir a realização de seus desejos.

Além de livre, todo ser humano é entendido, por Hobbes, como uma espécie de átomo de egoísmo ${ }^{3}$ que tende a satisfazer seus desejos mesmo que isso venha a subjugar

\footnotetext{
${ }^{2}$ Não existe um consenso acerca da questão do estatuto do estado de natureza em Hobbes. Isto é, por um lado é defendido que o estado de natureza hobbesiano diz respeito a um "fato histórico". Outros comentadores são ainda mais radicais acerca dessa questão e defendem que, além de ser um fato histórico, o estado de natureza consistiria numa espécie de "perigo permanente" o qual assombra constantemente a sociedade civil como uma ameaça que, a qualquer momento, poderá sobrevir (Cf. RYAN, 2011, p. 266). Por outro lado, há quem sustente que o estado de natureza em Hobbes se restrinja a uma ferramenta conceitual constituindo-se apenas como um "estado hipotético" (Cf. STEPHEN, 2007, p. 120). Essa observação já havia sido realizada no artigo de MELO NETO; SANTOS, 2018. Ainda nesse sentido, trazemos a citação do próprio autor que não nos deixa claro sobre seu posicionamento acerca do estatuto do estado de natureza: "Poderá porventura pensar-se que nunca existiu um tal tempo, nem uma condição de guerra como esta, e acredito que jamais tenha sido geralmente assim, no mundo inteiro; mas há mitos lugares onde atualmente se vive assim. Porque os povos selvagens de muitos lugares da América [...] não possuem nenhuma espécie de governo [...]. Mas mesmo que jamais tivesse havido um tempo em que os indivíduos se encontrassem numa condição de guerra de todos contra todos, de qualquer modo em todos os tempos os reis, e as pessoas dotadas de autoridade soberana, por causa de sua independência vivem em constate rivalidade, [...] o que constitui uma atitude de guerra" (HOBBES, 1999, p. $110)$.

${ }^{3}$ Nesse ponto, Hobbes estaria lançando mão de uma crítica à compreensão aristotélica do homem como um "animal político", isto é, a ideia pressuposta de que os homens possuiriam uma inclinação natural para a vida política, tal como aconteceria com os outros animais. No entender do filósofo inglês, “a vida do homem
} 
ou destruir outros indivíduos ${ }^{4}$. Isto é, na medida em que todos procuram atender as suas vontades, cria-se uma situação conflituosa de instabilidade e tensão no meio em que vivem, pois "[...] se dois homens desejam a mesma coisa, ao mesmo tempo que é impossível ela ser gozada por ambos, eles tornam-se inimigos" (HOBBES, 1999, p. 108). Tendo isso em mente, é possível notar que o estado de natureza promove um incessante sentimento de insegurança dos homens frente aos seus demais. Ora, se todos possuem direitos incondicionais sobre tudo, inclusive sobre os outros homens ${ }^{5}$, engendra-se aqui uma perpétua disposição para guerra:

E dado que a condição do homem [...] é uma condição de guerra de todos contra todos, sendo neste caso cada um governado por sua própria razão, e não havendo nada, de que possa lançar mão, que não possa servir-lhe de ajuda para a preservação de sua vida contra seus inimigos, segue-se daqui que numa tal condição todo homem tem direito a todas as coisas, incluindo os corpos dos outros. Portanto, enquanto perdurar este direito de cada homem a todas as coisas, não poderá haver para nenhum homem (por mais forte e sábio que seja) a segurança de viver todo o tempo que geralmente a natureza permite aos homens viver. (HOBBES, 1999, p. 113)

Hobbes argumenta que, nesse contexto desregrado e calamitoso, a razão humana seria capaz, contudo, de acessar as leis de natureza. Estas consistiriam em regras gerais da racionalidade humana, as quais vedam ao indivíduo a prática de qualquer ação que pudesse vir a destruir sua própria vida. Ora, no entender do autor do Leviatã , esse dado seria capaz de modificar o cenário de total desimpedimento que caracteriza o estado de natureza. Isso porque o uso da razão faria com que a lei de natureza se sobrepusesse ao direito natural, fato que levaria os homens a abdicarem da sua liberdade irrestrita - intrínseca ao direito natural. Ora, na ótica de Hobbes, seria justamente esse movimento de subordinação do direito natural às leis de natureza que daria sentido à fundação do Estado.

\subsection{0 contrato social e a fundação do Estado}

Diante da situação de vulnerabilidade e temor da morte, os homens são motivados, como que por um instinto de autopreservação e por uma ponderação racional, a estabelecer acordos de paz. Isso quer dizer que, por vontade própria, eles fixam as regras de convívio social cujo critério consiste na defesa e na conservação da própria vida por meio da interrupção do estado de guerra. Em síntese, esses acordos serviriam para possibilitar a todos os homens gozar de seu bem original, isto é, desfrutar sua própria vida sem que haja ameaça por parte de outros indivíduos.

é solitária, pobre, sórdida, embrutecida e curta" (HOBBES, 1999, p. 109), e, portanto, não haveria espaço para uma espécie de consenso espontâneo baseado numa atração natural à vida social. Nesse sentido, ocorreria que os demais animais seriam sociáveis e gregários, mas não políticos. Isso porque, os demais animais se congregam por um bem comum que não difere do "bem" de cada animal, ao passo que os homens diferenciam o bem privado do público. Portanto, diferente do que nos dizia Aristóteles, a filosofia hobbesiana nos leva a perceber que "os homens podem viver juntos apenas com base em princípios estabelecidos por acordo" (RYAN, 2011, p. 265).

${ }^{4}$ Neste contexto, é possível observar que é próprio da natureza do homem apossar-se, por meio da violência, das pessoas e dos bens alheios, sejam estes bens matérias ou até mesmo da liberdade e da vida de outros indivíduos. Ou seja, Hobbes entende que existiria uma disposição natural para uma competição violenta que move os homens a se "tornarem senhores das pessoas, mulheres, filhos e rebanhos de outros homens [...]" (HOBBES, 1999. p. 109). A esse respeito, Wollmann entende que “[o estado de natureza] é um estado de total degradação. A única regra de moralidade neste estado é o egoísmo individualista e interesseiro, que é a luta competitiva incessante de cada um pelo poder sobre o outro, a única regra de direito natural, a utilidade, o bem comum, a própria conservação e o proveito próprio" (WOLLMANN, 1993, pp. 33-34).

${ }^{5}$ No estado de natureza, não há nada que o homem não tenha direito por natureza, e por essa razão, todos os indivíduos estão igualmente sujeitos a apropriação e subjugação de outros homens. Ainda nesse sentido, não é possível conceber tais ações como injustas, pois o próprio conceito de justiça só passaria a existir na vida em sociedade. "A justiça e a injustiça não fazem parte das faculdades do corpo ou do espírito. [...] São qualidades que pertencem aos homens em sociedade, não na solidão" (HOBBES, 1999, p. 110). 
Consequentemente é um preceito ou regra geral da razão, Que todo homem deve esforçar-se pela paz, na medida em que tenha esperança de consegui-la [...]. A primeira parte desta regra encerra a lei primeira e fundamental de natureza, isto é, procurar a paz, e segui-la [...]. (HOBBES, 1999, p. 114)

Como foi possível acompanhar, as leis naturais incitariam os acordos firmados por homens que pretendem conter o medo alastrado pelo estado de natureza ${ }^{6}$. Isso significa uma solução adotada de forma racional e deliberada que visa, precisamente, à conservação das vidas que se encontram ameaçadas por um contínuo perigo do ilimitado direito natural. Dessa forma, pode-se afirmar que os acordos sociais funcionam como uma espécie de fundamento para a instauração das normas de restrição da conduta humana. Mas, embora essas leis sejam estabelecidas por uma mútua concordância e apontem para a defesa de um "bem comum" a todos os indivíduos, podemos observar que, até o momento, nada foi dito a respeito de uma validação das palavras que constituem esses acordos. Isto é, o que poderia garantir o cumprimento dessas regras visto que, naturalmente, o homem possui o direito sobre tudo e que a satisfação de seus desejos poderia ocasionar a privação ou aniquilação do direito alheio?

É nesse sentido que Hobbes identifica a necessidade de um poder comum responsável por firmar e manter sólido o acordo social. Ou seja, um princípio regulador capaz de sustentar a obrigatoriedade das promessas estabelecidas. É neste ponto que seria necessário instaurar uma instituição soberana à qual todos os homens haveriam de transferir seus direitos a serviço de uma vontade coletiva. Com efeito, apenas dessa maneira seria possível superar a situação de risco e incerteza gerada pelo estado de guerra e, consequentemente, alcançar as condições de um estado de paz.

A fundação do Estado, portanto, acontece com o objetivo de garantir a proteção e conservação da vida, constantemente ameaçada pelo estado de natureza que, como foi visto, é resultado de um acordo racional entre os homens que temem os perigos da guerra de todos contra todos. Assim, a fim de assegurar o bem original da vida e superar o "estado selvagem", os homens, livremente, dão consentimento ao contrato social. Ou seja, todos submetem suas vontades à vontade do poder soberano que deve discernir sobre assuntos concernentes à paz civil.

A única maneira de instituir um tal poder comum, capaz de defende-los das invasões dos estrangeiros e das injúrias uns dos outros, garantindo-lhes assim uma segurança suficiente [...] é conferir toda sua força e poder a um homem, ou a uma assembleia de homens, que possa reduzir suas diversas vontades, por pluralidade de votos, a uma só vontade. (HOBBES, 1999, pp. 143-144)

Entretanto, nem todos os homens se pautam pela razão e, em condição de igualdade de poder, eles são levados a disputar uns contra outros, o que pode ocasionar a ruptura dos acordos de paz. Seguindo esse raciocínio, Hobbes identifica que para fixar respeito às leis e impor a obrigatoriedade do cumprimento dos acordos, o Estado tende a atuar por meio da violência. Os contratos sociais, desse modo, terão suas bases fundadas na obediência civil e no controle exercido pelo Estado. Isto quer dizer que o Estado teria poder para usar de força coercitiva a fim de manter selado o contrato entre os homens. Isso porque, no entender do autor, apenas o temor dos castigos os condicionaria a respeitar as leis instituídas pelo Estado. Dessa forma, a força da instituição soberana à qual todos devem seus direitos se traduziria em outras leis que

\footnotetext{
${ }^{6}$ A respeito disso, verificar o comentário de Wollmann: “A libertação, a salvação, consiste exatamente em o homem abandonar tal estado de natureza. A possibilidade de abandonar tal estado o homem a possui. Consiste em parte nas paixões e, em parte, na razão. Algumas das paixões o inclinam para a paz, entre elas, o temor da morte, que ameaça o homem. A razão, que é somente cálculo, sugere-lhe artigos de paz, que lhe permite entrar em acordo com os outros homens. Hobbes chama a estes mecanismos que nos assegura a paz, estes preceitos racionais, de leis naturais" (WOLLMANN, 1993, p. 47).
} 
coíbem qualquer ato que possa perturbar o contrato que fora volitiva e racionalmente estabelecido. Isso significa, em outras palavras, que as leis de natureza são mantidas invioláveis não por respeito ou por uma escolha racional, mas, sobretudo, pelo temor de alguma punição ${ }^{7}$.

\section{A hipótese nietzschiana acerca do aparecimento do Estado}

\subsection{A fundação do Estado como um ato de violência}

Nas seções 16 e 17 da segunda dissertação da Genealogia da moral, Nietzsche propõe uma hipótese acerca do surgimento do Estado. Assim como Hobbes, o filósofo alemão compreende que esse momento caracterizar-se-ia numa espécie de ruptura do ambiente no qual a humanidade está naturalmente inserida. Na ótica nietzschiana, tal como os outros animais, o homem seria constituído por impulsos violentos de dominação e destruição que exigem, a todo instante, a própria satisfação. Assim, no período pré-político, não havendo qualquer tipo de lei reguladora, ele se encontraria desimpedido de exteriorizar sua animalidade violenta contra outros indivíduos pelo simples "prazer na perseguição" (NIETZSCHE, 2015, p. 68). Nesse sentido, o "bicho-homem" tenderia a agir conforme sua condição de selvageria natural e, por essa razão, descarregaria toda sua agressividade de maneira espontânea e livre.

Nos termos do autor, podemos definir o homem como vontade de potência ${ }^{8}$. Conforme essa perspectiva, tudo seria constituído e movido conforme configurações de afetos agressivos, promovendo, dessa maneira, relações belicosas de paixões e desejos no ambiente humano. Assim como cada um desses afetos característicos exige a sua efetivação, também as ações humanas se pautam segundo essas mesmas linhas: cada ação seria resultado dos afetos que desejam se efetuar como força de subjugação sobre os outros afetos, gerando, dessa forma, uma constante guerra por mais poder. Ora, se o homem é constituído por essa multiplicidade de forças e as forças estão em constante combate entre si, então a luta entre os homens não seria delimitada por um fim último a ser alcançado, mas representaria um incessante anseio por mais potência ${ }^{9}$.

Ainda nessas passagens supracitadas, o filósofo do martelo defende que as condições que direcionam a humanidade ao âmbito da sociedade de paz consistiriam, na realidade, num "ato de violência" que teria submetido um grupo de homens às ordens de outros mais fortes. Isso significa que, em determinado momento da

\footnotetext{
${ }^{7}$ A esse respeito, é possível fazer uma comparação entre Estado e religião, pois, pode-se compreender que ambos ganhariam força na intimação de um povo, o que mais tarde de transformaria em reverência ou crença: “Esse respeito capaz de intimidar a todos ou aquele que é capaz de manter todos em temor respeitoso a essa reverência, ao assombro que os homens devem experimentar diante de uma representação de transcendência promovida pela religião ou pelo Estado. Na origem da religião e do Estado encontramos o medo e depois, como resultado, a intimidação ou a crença. A transição é feita por [...] uma ficção criada pelos homens [...]. Dessa forma, para Hobbes o poder do Estado é baseado não só no medo natural, mas também em sua transformação em crença ou reverência" (SOUKI, 2009, pp. 165-166).

${ }^{8}$ Acerca da noção nietzschiana de vontade de potência, conferir o capítulo primeiro de MARTON, 2010.

${ }^{9}$ Compreendendo o homem enquanto vontade de potência, Nietzsche lançará críticas à noção cartesiana de sujeito. Um dos marcos da filosofia moderna, o cogito cartesiano exprime a certeza da existência de um "eu" pensante antecedente às ações humanas. A partir disso, será fomentada a crença de que o homem é capaz de deliberar acerca de suas atitudes (Cf. DESCARTES, 1999, p. 258). Contudo, no entender do filósofo alemão, essa concepção de sujeito seria, na realidade, o fruto de um enganado gramatical que teria levado René Descartes a afirmar a existência de uma possível substância, presente em cada indivíduo, responsável por seu pensamento. Pensar que toda ação exige um agente, diz Nietzsche, seria apenas uma sedução da linguagem "a qual entende ou malentende que todo atuar é determinado por um atuante, um 'sujeito'" (NIETZSCHE, 2009 p. 33).
} 
história, homens de aflorado instinto de dominação - os "senhores" -, ao imporem certa organização do meio, exerceram sua força sobre aqueles vistos como os mais fracos - os "escravos". Conforme essa tese, o "Estado" teria surgido da tirania dos senhores sobre uma massa de escravos que não conseguiriam se organizar sem alguma forma de repressão.

Tento em mente esse cenário, pode-se afirmar que Nietzsche entende que o "Estado" seria fruto dessa conquista violenta dos mais fortes sobre os fracos. No entender do pensador alemão, aquele que "por natureza é 'senhor', quem é violento em atos e gestos" - os "organizadores natos" - impõe as leis pertinentes à vida coletiva de toda uma população. Nesse sentido, somente por meio da coerção dos "senhores" sobre os "escravos" é possível enxergar a inserção de uma estabilidade social ${ }^{10}$. Conforme a reflexão nietzschiana, portanto, as normas estatais não seriam determinadas por meio de uma concessão deliberada que tem por fim a superação do estado selvagem. A mudança de um estágio a outro não seria dada de maneira "gradual, nem voluntária", mas através de "[...] uma ruptura, um salto, uma coerção, uma fatalidade inevitável [...]" (NIETZSCHE, 2009, p. 69). Além do mais, a violência não cessaria com a instauração de uma instituição organizadora como o Estado, pois, como veremos mais adiante, o homem tende a manifestar sua agressividade ainda que esteja dentro de determinadas normas. Aliás, o que manteria o respeito a essas normas seria, justamente, a violência e as ameaças de castigos utilizadas como meio de criar uma memória: "“Como fazer no bicho-homem uma memória? [...]' ‘Grava-se algo a fogo, para que fique na memória: apenas o que não cessa de causar dor fica na memória' - eis um axioma da mais antiga (e infelizmente mais duradoura) psicologia da terra" (NIETZSCHE, 2009, p. 46).

Desse modo, a ideia da fundação de um "Estado" passa a ser entendida como o resultado da ação coercitiva de uma classe de senhores dominantes, a qual Nietzsche designa como a "sociedade" das bestas louras. Isto é, o fruto de uma imposição de regras dos homens mais fortes sobre uma massa de homens fracos. Por fim, podemos concluir que com isso o filósofo alemão procura distanciar-se completamente da ideia de um contrato social legitimado pelo poder do Estado.

Utilizei a palavra "Estado": está claro a que me refiro - algum bando de bestas louras, uma raça de conquistadores e senhores, que, organizada guerreiramente e com força para organizar, sem hesitação lança suas garras terríveis sobre uma população talvez imensamente superior em número, mas ainda informe e nômade. Deste modo começa a existir o "Estado"; na terra: penso haver-se acabado aquele sentimentalismo que o fazia começar com um "contrato". (NIETZSCHE, 2009, p. 69)

Nietzsche identifica que o Estado, com o objetivo de conter os indivíduos de sua livre expressão da violência, determina as leis comportamentais dentro do âmbito da sociedade civil e, nesse sentido, todo comportamento considerado agressivo à vida coletiva é detido. De tal maneira, o Estado funciona como uma organização coercitiva que utiliza da força e de ameaças de castigos para submeter os homens às normas da vida gregária. Isto é, aqueles "organizadores natos" utilizam da imposição de suas leis para criar uma relação austera sobre a "sociedade" dos homens fracos e, desta maneira, ditam a forma como estes devem passar a agir.

\subsection{A consciência moral como epifenômeno da fundação do Estado}

\footnotetext{
${ }^{10}$ A respeito disso, o autor nos dirá, ainda: "A inserção de uma população sem normas e sem freios numa forma estável, assim como tivera início com o ato de violência, foi levada a termo somente com atos de violência [...]" (NIETZSCHE, 2009, p. 69).
} 
Seguindo essa linha de raciocínio, Nietzsche conclui que, após o advento do "Estado", o homem passou a ser impedido de satisfazer os impulsos violentos que o constituem, pois eles seriam considerados nocivos à vida coletiva. Dessa maneira, as novas normas impostas promovem uma grande reviravolta no comportamento do homem: ele se encontraria limitado a agir conforme regras que inibem a livre expressão de seus impulsos; sua violência característica tende a voltar contra ele mesmo. Ora, se no primeiro momento o homem se encontrava num mundo ausente de leis reguladoras e barreiras morais e, por esse motivo, ele podia expressar livremente sua animalidade, com a instauração do "Estado" e suas constantes ameaças de castigos, veremos que o homem é obrigado a adaptar-se a uma vida privada da livre disputa, da perseguição ao inimigo, da hostilidade e da crueldade que lhe são próprias...

[...] os velhos instintos não cessaram repentinamente de fazer suas exigências! Mas era difícil, raramente possível, lhes dar satisfação: no essencial tiveram de buscar gratificações novas e, digamos, subterrâneas. Todos os instintos que não se descarregaram para fora voltam-se para dentro [...]. (NIETZSCHE, 2009, p. 67)

É nesse sentido que Nietzsche argumenta acerca do surgimento da ideia de consciência moral - ou, como diz o filósofo, a má-consciência. Essa noção, tradicionalmente, designa o caráter moral das ações humanas. Isto é, ela consistiria numa espécie de julgamento interno capaz de delimitar quando e qual comportamento é aceitável ou condenável pelo meio social. No entender do autor, o surgimento desse "sentimento" estaria intimamente relacionado à instauração da "sociedade de paz", deslegitimando, assim, as teorias que validam o inatismo da consciência moral.

Vejo a má-consciência como a profunda doença que o homem teve de contrair sob a pressão da mais radical das mudanças que viveu - a mudança que sobreveio quando ele se viu definitivamente encerrado no âmbito da sociedade de paz. (NIETZSCHE, 2009, p. 67)

Portanto, sob as condições de pressão gerada pela regência do Estado e a consequente mudança no ambiente - isto é, a ruptura do homem com seu habitat natural provocada pelas novas leis vigentes - surgirá a má-consciência.

Aqueles terríveis bastiões com que a organização do Estado se protegia dos velhos instintos de liberdade - os castigos, sobretudo, estão entre esses bastiões - fizeram com que todos aqueles instintos do homem selvagem, livre e errante se voltassem para trás, contra o homem mesmo. A hostilidade, a crueldade, o prazer na perseguição, no assalto, na destruição - tudo isso se voltando contra os possuidores de tais instintos: esta é a origem da má-consciência (NIETZSCHE, 2009, pp. 67-68).

Se levarmos em conta o contexto da doutrina da vontade de potência, podemos concluir que a violência característica do homem exige exteriorizar-se, isso porque ele é constituído por impulsos que têm por necessidade expandirem-se, causando, de tal maneira, embates belicosos. Nessa perspectiva, o seu instinto animal não seria aniquilado de maneira repentina e, à procura de um novo sentido, o homem passaria a agredir a si mesmo. Isso quer dizer que, mesmo que impedido de agir segundo sua animalidade, o homem não deixaria de ser violento, e por esse motivo ele passaria a usar de sua própria violência contra si mesmo: "Esse instinto de liberdade reprimido, recuado, encarcerado no íntimo, por fim capaz de desafogar-se somente em si mesmo: isto, apenas isto foi em seus começos a má consciência" (NIETZSCHE, 2009, p. 69).

\section{Nietzsche e Hobbes: convergências e divergências}

É possível constatar, portanto, que há relações de proximidade entre as filosofias de Nietzsche e Hobbes. No tocante à compreensão do estágio pré-político da humanidade, como pudemos acompanhar, ambos os pensadores consideram 
que, na ausência de rígidas normas de conduta, o homem tende a expressar-se espontaneamente de maneira violenta, subjugando outros e se apossando do que é alheio a ele simplesmente porque assim sua natureza o permite ser. Todavia, com o surgimento do Estado, o homem torna-se "moldado" e obrigado a agir de maneira diferente da habitual. Aqui, encontramos, ainda, outro ponto de congruência entre os pensadores: ambos percebem que o Estado utiliza da força coercitiva para com a sociedade a fim de que esta siga suas leis. Dessa maneira, destacamos três pontos de afinidade entre os pensadores: 1) o homem é constituído por incessante desejo de poder e, por isso, é um ser violento por natureza; 2 ) em seu estágio selvagem, ou seja, sem a presença de ordens de um poder superior, ele pode exercer seus instintos violentos de forma livre e 3) o Estado é compreendido como instituição de poder superior que utiliza de força punitiva sobre os homens para garantir a ordem, ou seja, a estabilidade social é alcançada apenas por meio da força de coerção que intimida os homens a manter respeito em relação ao Estado ${ }^{11}$.

No entanto, temos de observar que Nietzsche toma distância da teoria contratualista à medida que compreende o Estado como fruto da ação agressiva de homens fortes que submetem os homens fracos a seu mando. Portanto, não haveria sentido a ideia de um contrato estabelecido entre as partes, visto que o que ocorre, no seu entender, seria uma relação de dominação de uns sobre outros, e não um acordo que visa à saída do estágio selvagem em busca de sua superação ${ }^{12}$. Ainda nesse sentido, o homem forte não corresponderia a alguém que poderia escolher acerca do uso ou da abstenção de sua força, pois, no contexto nietzschiano, ele seria a expressão da força atuando enquanto força. Nessa perspectiva, o Estado consiste numa organização de homens que são, em última instância, forças se exercitando como tal, não restando, assim, espaço para a compactuação de acordos volitivamente delimitados. Segundo Nietzsche, haveria apenas a atuação impositiva dos fortes sobre os mais fracos.

No que diz respeito à moral, nosso autor evidencia, ainda, que a má-consciência seria uma consequência das novas configurações impostas pelo Estado. Em linhas gerais, o filósofo alemão compreende a consciência como resultante de processos orgânicos e sociais, não como um princípio inato capaz de fundamentar e direcionar o comportamento moral de cada indivíduo. Isso quer dizer que a "consciência moral" não nasceria com os homens, e, desse modo, eles não seriam naturalmente capacitados para discernir acerca das ações que seriam mais ou menos justas - indo de encontro à noção moderna de um sujeito "livre e pensamente". Nietzsche sublinha ainda que a origem da má-consciência encontra-se intimamente vinculada ao surgimento do Estado, que, por meio de regras que castram a livre expressão da violência do homem, os direcionaria a um novo comportamento. Dessa maneira, a vida em sociedade impediria a exteriorização de sua energia violenta que, num ambiente selvagem, é expressa naturalmente e sem repressão contra outros indivíduos. Essa mesma energia, quando impedida de ser lançada para fora, volta-se contra o próprio homem, causando-lhe o sentimento de culpa por qualquer atitude que não tenha sido definida como conveniente à vida coletiva.

Encontramos, dessa maneira, o principal ponto de afastamento entre os filósofos: o pensamento de Hobbes pressupõe a existência de um sujeito ético que, guiado

\footnotetext{
${ }^{11}$ Neste ponto, é importante ressaltar que não foi o objetivo deste trabalho abordar uma reflexão acerca das relações entre Nietzsche e Hobbes no que diz respeito à questão do poder. Sobre esse tema, é preciso, ainda, se debruçar, principalmente, no capítulo X do Leviatã.

${ }^{12}$ Podemos entender ainda que, como visto, o filósofo alemão subverte a noção moderna de sujeito, o que invalida totalmente a ideia de um consenso racional em busca do estado de paz. Ora, o homem entendido enquanto vontade de potência não pressupõe uma capacidade deliberativa do querer humano. Isso porque não existiria um substrato racional por trás da vontade, capaz de calcular e premeditar as ações, mas apenas as próprias ações como fruto da configuração de seus impulsos e afetos. Ainda sobre a crítica nietzschiana à noção de sujeito, vale conferir ONATE, 2000.
} 
por princípios racionais, visa a atingir uma relação harmoniosa no âmbito social. Entretanto, segundo a filosofia de Nietzsche, não haveria essa suposta consciência moral inerente ao homem que o tornaria capaz de estabelecer acordos de paz. A prova disso, no contexto da Genealogia da moral, decorre de que os "senhores" não possuiriam a má-consciência, pois estes, ao dominarem outros indivíduos, dão vazão à sua agressividade de forma livre, obedecendo, assim, à sua própria vontade. Portanto, a consciência moral é tida como resultante da imposição promovida pelas bestas louras sobre os "escravos".

Neles [nos senhores] não nasceu a má consciência, isto é mais que claro - mas sem eles ela não teria nascido, essa planta hedionda, ela não existiria se, sob o peso de seus golpes de martelo, da sua violência de artistas, um enorme quantum de liberdade não tivesse sido eliminado do mundo, ou ao menos do campo de visão, e tornado como que latente. (NIETZSCHE, 2009, p. 70)

\section{Conclusão}

É possível concluirmos, portanto, que a filosofia de Nietzsche não pode ser entendida à luz da perspectiva moderna do contratualismo. Isso porque o autor alemão vai totalmente de encontro à noção de contrato, uma vez que interpreta o surgimento do Estado como o resultado da imposição violenta dos mais fortes sobre as massas humanas. Nesse sentido, ele é completamente contrário à ideia de que a saída do estado selvagem seja fruto de um consenso entre indivíduos que almejam atingir um "bem comum" por intermédio da fundação de uma instituição soberana. Dessa maneira, Nietzsche entenderia o "contrato" como uma espécie de "sentimentalismo" que estaria enraizado em ideais cristãos. Em outras palavras, da mesma forma que nos demais contratualistas modernos ${ }^{13}$, seria possível encontrar na teoria hobbesiana resquícios de valores que se pautam na doutrina do cristianismo. Isto é, ao pressupor que todos os homens seriam naturalmente iguais e que eles poderiam entender-se pacificamente por meio de acordos, Hobbes estaria, inconscientemente, partindo de um "preconceito" cristão, a saber, a ideia de igualdade original dos homens frente a Deus. A esse respeito, um fragmento da primavera de 1888 - redigido poucos meses após a publicação de Genealogia da moral - é bem ilustrativo:

Outro conceito cristão, não menos louco, foi transmitido por herança, de maneira mais profunda, na carne da Modernidade: o conceito de igualdade das almas perante Deus. Nele se encontra o protótipo de todas as teorias de igualdade de direitos: primeiro, ensinou-se à humanidade a titubear religiosamente sobre o principio da igualdade; a partir disso, foi constituída uma moral: e, que surpresa! O ser humano acaba levando isso a sério, colocando-o em prática!, quer dizer, politicamente [...]. (NIETZSCHE, 2008, p. 636)

Concluímos, portanto, que a hipótese nietzschiana acerca do surgimento do Estado e a sua crítica ao contratualismo impelem-nos a repensar a relação do homem ocidental com suas instituições mais fundamentais.

Correspondência: Isabela Gonçalves Dourado. Universidade Católica de Pernambuco - UNICAP. Rua do Príncipe, 526. Boa Vista. Recife - PE - Brasil. CEP: 50050-900. E-mail: gdouradoisa@gmail.com. Apoio financeiro: PIBIC.

Conflito de interesses: Nenhum.

Todos os autores leram e aprovam a versão final submetida à revista Em curso.

\footnotetext{
${ }^{13}$ Neste ponto, estamos seguindo de perto a posição de MELO NETO; SANTOS, 2018.
} 


\section{Bibliografia}

DESCARTES, R. Discurso sobre o método. Tradução de Enrico Corvisieri. São Paulo: Editora Nova Cultural, 1999.

HOBBES, T. Leviatã ou matéria, forma e poder de um estado eclesiástico e civil. Tradução de João Paulo monteiro e Maria Beatriz Nizza da Silva. São Paulo: Nova Cultura, 1999.

MARTON, S. Nietzsche, das forças cósmicas aos valores humanos. Belo Horizonte: UFMG, 2010.

MELO NETO, J; SANTOS, A. Convergências e divergências entre Nietzsche e a tradição contratualista moderna: a noção nietzschiana de "Estado" nas seções 16 e 17 da segunda dissertação de Genealogia da moral. Cadernos Nietzsche, Porto Seguro, v. 39, n. 1, p. 31-53, 2018. Disponível em http:/ / www.scielo. br/pdf/cniet/v39n1/2316-8242-cniet-39-01-31.pdf. Acesso em: 05/08/2018.

NIETZSCHE, F. Genealogia da moral. Tradução de Paulo César de Sousa. São Paulo: Companhia das Letras, 2005.

.Fragmentos póstumos: Volumen IV (1885-1889). Tradución de Juan Luis Vermal y Joan B. Llinares. $2^{\text {a }}$ edición. Madrid: Tecnos, 2008.

ONATE, A. M. O crepúsculo do sujeito em Nietzsche ou como abrir-se ao filosofar sem metafísica. São Paulo: Discurso; Ijuí: Editora Unijuí, 2000.

RYAN, A. A filosofia política de Hobbes. In: SORELL, T. (Org.). Hobbes. Tradução de André Oídes. São Paulo: Ideias \& Letras, 2011. p. 253-297.

SOUKI, N. Da guerra civil de Hobbes às guerras nossa de cada dia. In: VILLANOVA, M.; BARROS, D. (Org.). HOBBES: natureza, história e política. São Paulo: Discurso Editorial, 2009, p.153-167

WOLLMANN, S. O conceito de liberdade no Leviatã de Hobbes. Porto Alegre. EDIPUCRS, 1993.

Recebido em: 31/Mai/2018 - Aceito em: 22/Ago/2018. 